Volume 1, Number 2, July 2019

\title{
Original Article \\ Awareness regarding personal hygiene and sanitation practices among adult population in Dhamrai, Dhaka
}

\author{
Sultana Begum ${ }^{1}$, Monowar Ahmad Tarafdar ${ }^{2}$, Md Saizuddin $^{3}$, Nadia Begum ${ }^{4}$, Shila Rani Das ${ }^{5}$, Meheruba Afrin $^{6}$
}

\begin{abstract}
The current descriptive type of cross sectional study was conducted during $16^{\text {th }}$ May to $31^{\text {st }}$ May 2018 to assess awareness regarding personal hygiene and sanitation practices in Dhamrai, Dhaka with a sample size of 120 using interviewer administered semi-structured questionnaire employing convenience sampling technique. More than one third (35.9\%) of the respondents were in age group $25-35$ years and about $65 \%$ were female, $32.5 \%$ were housewives and $35.8 \%$ were found illiterate. source of drinking water was from $71.67 \%$ tube well and $78.3 \%$ used sanitary latrine. More than half of the respondents $(61.67 \%)$ were taking daily bath with soap and water, $61.66 \%$ cut their nails at leisure time and $51.67 \%$ wash hair with shampoo and water; while $59.67 \%$ washed their hands before meal and $76.67 \%$ after defecation with soap and water. It is revealed that $43.3 \%$ were aware about the transmission of diarrheoa through dirty nail and $73.3 \%$ were aware not to defecate on barefoot. Health education and comprehensive knowledge of proper personal hygiene and sanitation is essential in daily life and should be used to prevent the spread of infectious diseases.
\end{abstract}

Keywords: Awareness, Personal hygiene, Sanitation, Transmissible Diseases.

\section{Introduction}

Health awareness and practices is an essential part of human life in the process of active learning process. Inadequate hygiene and sanitation has direct effect on health of an individual, family, communities and nation as a whole. Toilet is considered as an essential and basic indicator of health and sanitation worldwide. ${ }^{1}$ Proper sanitation is a necessary prerequisite for improvement in general health standards, productivity of labor force and good quality of life. ${ }^{2}$ It is just alarming that in every 20 seconds, a child around the world dies as a result of poor sanitation. ${ }^{3}$ About $80 \%$ of all diseases of the developing world is related to drinking unsafe water and inadequate sanitation. ${ }^{4}$ Worldwide, $5.3 \%$ of all deaths and $6.8 \%$ of all disability are caused by poor sanitation, poor hygiene and unsafe water. Nearly two-thirds (67\%) of the total population go for open-air defecation and only one-third (33\%) having access to a latrine. ${ }^{5}$

In a developing country like Bangladesh, almost one-third of the population lives below the poverty line. Various diseases are rampant due to lack of safe drinking water and sanitation. ${ }^{6}$ Among the poorest, nearly one-third defecate in the open, making the everyday environment unsafe. ${ }^{7}$ According to a World Health Organization
(WHO) estimate, 1.5 million children die from diarrheoal diseases each year worldwide, with $88 \%$ of these deaths occurring due to inadequate sanitation, hygiene, and safe drinking water. ${ }^{8}$ So, hygiene practice becomes difficult in many parts of the world, including Bangladesh, due to lack of awareness about using safe water, soap and disinfectants. ${ }^{9}$ Only $26.7 \%$ people wash their hands with soap or ashes after defecation. ${ }^{10}$ The main barrier to success of sanitation coverage is lack of awareness about the benefits of a safe latrine, poverty, lack of adequate space, and attitude for open defecation. ${ }^{11}$ In this regard, Government of Bangladesh initiated a program to achieve 100\% sanitation by 2013 .

\section{Materials and Methods}

This descriptive type of cross sectional study conducted to assess awareness regarding personal hygiene and sanitation practices in Dhamrai, Dhaka during $16^{\text {th }}$ May to $31^{\text {st }}$ May 2018 with a sample size of 120 using interviewer administered semi-structured questionnaire employing convenience sampling technique. After collection, the data were checked, verified and edited. Compilation and tabulation of data according to key variables was done by using calculator and computer. Data were presented by tables and diagrams based on nature of data.

1. Associate Professor, Department of Community Medicine, Z H Sikder Women's Medical College, Dhaka

2. Professor, Department of Community Medicine, Z H Sikder Women's Medical College, Dhaka

3. Professor, Department of Community Medicine, Z H Sikder Women's Medical College, Dhaka

4. Associate Professor, Department ofCommunity Medicine, Z H Sikder Women's Medical College, Dhaka

5. Associate Professor, Department ofCommunity Medicine, Z H Sikder Women's Medical College, Dhaka

6. Assistant Professor, Departmentof Community Medicine, Z H Sikder Women's Medical College, Dhaka

Address of correspondence:

Sultana Begum, Associate Professor, Department ofCommunity Medicine, Z H Sikder Women's Medical College, Dhaka. Email: sultanamallick24@gmail.com 


\section{Results}

This descriptive type of cross sectional study conducted to assess awareness regarding personal hygiene and sanitation practices in Dhamrai, Dhaka. While examining the socio-demographics characteristics, it was found that $35.9 \%$ were from 25 to 35 years age group, $65 \%$ were female and $35 \%$ male; $35.8 \%$ was found illiterate. House wives were $32.5 \%, 45 \%$ of the respondents had monthly income of 5000 to 10,000 taka. The current study revealed that $71.67 \%$ respondents used tube well as a source of drinking water and $78.33 \%$ of the respondents used sanitary latrine.

Table No. 1: Distribution of respondents regarding socio-demographic characteristics $(n=120)$

\begin{tabular}{|c|c|c|}
\hline Variables & Frequency & $\begin{array}{c}\text { Percentage } \\
(\%)\end{array}$ \\
\hline \multicolumn{3}{|l|}{ Age Group (year) } \\
\hline $15-25$ & 41 & 34.1 \\
\hline $25-35$ & 43 & 35.9 \\
\hline $35-45$ & 14 & 11.7 \\
\hline $45-55$ & 16 & 13.3 \\
\hline$>55$ & 6 & 5 \\
\hline \multicolumn{3}{|l|}{ Sex } \\
\hline Male & 42 & 35 \\
\hline Female & 78 & 65 \\
\hline \multicolumn{3}{|l|}{ Religion } \\
\hline Islam & 112 & 93.3 \\
\hline Hindu & 8 & 6.7 \\
\hline \multicolumn{3}{|l|}{ Educational Level } \\
\hline Illiterate & 43 & 35.8 \\
\hline Class I-IV & 18 & 15 \\
\hline Class V - X & 19 & 15.8 \\
\hline $\mathrm{SSC}$ & 16 & 13.4 \\
\hline HSC & 10 & 8.3 \\
\hline Graduation & 8 & 6.7 \\
\hline Masters & 6 & 5 \\
\hline \multicolumn{3}{|l|}{ Occupation } \\
\hline Housewife & 39 & 32.5 \\
\hline Service holder & 14 & 11.67 \\
\hline Day labourers & 6 & 5 \\
\hline Domestic helper & 13 & 10.83 \\
\hline Business & 8 & 6.67 \\
\hline Agriculture & 7 & 5.83 \\
\hline Driver & 5 & 4.17 \\
\hline
\end{tabular}

\begin{tabular}{lcc} 
Rickshaw puller & 13 & 10.83 \\
Carpenter & 1 & 0.83 \\
Masonry & 1 & 0.83 \\
Student & 14 & 10.84 \\
\hline Monthly Family & & \\
Income(Tk) & & \\
$<5000$ & 7 & 5.84 \\
$5000-10,000$ & 54 & 45.0 \\
$10,000-15,000$ & 43 & 35.83 \\
$>15,000$ & 16 & 13.13 \\
\hline
\end{tabular}

\section{Source of drinking water}

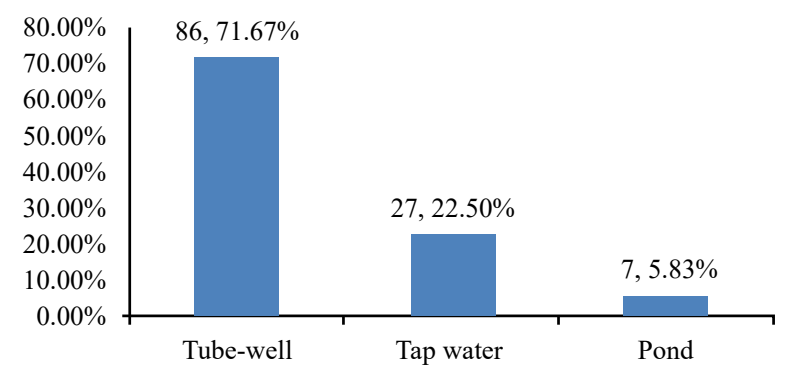

Figure 1: Bar-diagram showing distribution of respondents according to sources of drinking water.

Table No. 2: Distribution of respondents regarding personal hygiene $(n=120)$

\begin{tabular}{lcc}
\hline \multicolumn{1}{c|}{ Habit of bathing } & Frequency & $\begin{array}{c}\text { Percentage } \\
\text { (\%) }\end{array}$ \\
\hline Daily & 89 & 74.17 \\
At interval & 31 & 25.83 \\
\hline Method of taking bath & & \\
With water only & 34 & 28.33 \\
With soap \& water daily & 74 & 61.67 \\
With soap \& water at interval & 12 & 10 \\
\hline Habit of brushing teeth & & \\
Daily & 87 & 72.5 \\
At interval & 33 & 27.5 \\
\hline Habit of Cutting nails & & \\
Weekly & 37 & 30.34 \\
Fortnight & 16 & 13.33 \\
At only leisure time & 62 & 61.66 \\
Not at all & 5 & 4.17 \\
\hline Method of washing hair & & \\
With soap \& water & 34 & 28.33 \\
With shampoo \& water & 62 & 51.67 \\
With shampoo, soap \&water & 18 & 15
\end{tabular}




\begin{tabular}{lcc} 
Others & 6 & 5 \\
\hline $\begin{array}{l}\text { Method of Washing } \\
\text { hands after meal }\end{array}$ & \\
Only water & 41 & 34.67 \\
Soap \& water & 71 & 59.67 \\
Ash \& water & 2 & 1.67 \\
Nothing & 4 & 3.33 \\
Other & 2 & 1.67 \\
\hline Method of Washing & & \\
hands after defecation & & \\
Only water & 19 & 15.83 \\
Soap \& water & 90 & 75 \\
Mud \& water & 7 & 5.83 \\
Ash \& water & 4 & 33.33 \\
\hline
\end{tabular}

Kaccha Type of latrine used latrine,

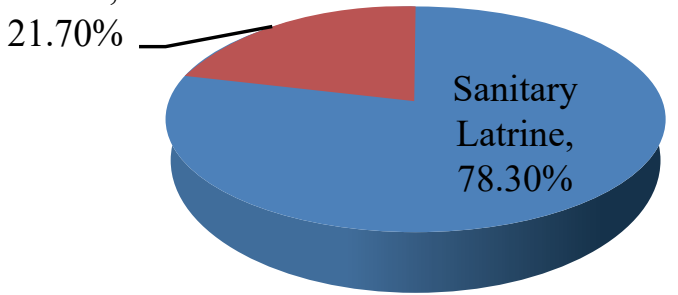

Figure 2: Pie diagram showing distribution of respondents according to type of latrine used.

\section{Diseases transmitted by dirty nail}

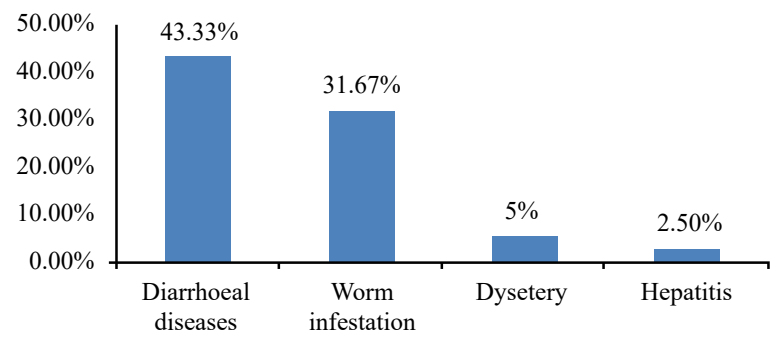

Figure 3: Bar-diagram showing distribution of respondents by knowledge on Transmission of worm infestation through dirty nail.

\section{Defecation barefoot}

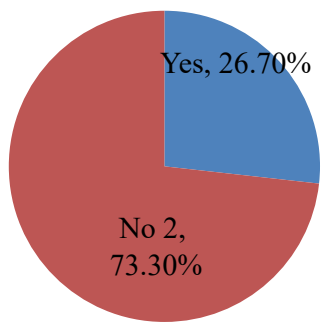

Figure 4: Pie diagram showing distribution of respondents who defecates barefoot.

\section{Discussion}

In this study, $60 \%$ respondents had good personal hygiene practice and $40 \%$ did not practice adequate hygiene and $78.33 \%$ of the houses showed good sanitary condition. Slightly different picture was observed in Nepal by Rajiv Ranjan Karn, Buna Bhandari, and Nilambar Jha where they found the sanitary knowledge had $90 \%$ respondents and hand washing with soap water of $65 \%$ of the community people was high. ${ }^{12}$

In this study, $78.3 \%$ of the houses had sanitary latrine and the respondents had toilet facilities and they do not use open air defecation. Almost similar data was presented in a study conducted in Dhaka in $2014 .{ }^{13}$ Overall, the majority $59.67 \%$ reported washing hands with soap and water; $34.67 \%$ washing hands with only water before taking meals. These findings are almost similar in the studies carried out in Jahangirnagar University in 2012 by Mashura Shammi and Mahedi Morshed. ${ }^{14}$

In this study, $75 \%$ of the respondents reported washing hands with soap and water after defecation, and 34.67\% washing hands with water after defecation. Slightly different findings were observed in Bangladesh National Hygiene Baseline Survey 2014. ${ }^{15}$ Approximately 74\% of the respondents reported daily bathing practices and $72 \%$ reported tooth brushing practices. These findings are dissimilar with the findings of a study conducted in Quatar which showed that 35\% of respondent reported poor bathing. ${ }^{16}$

This current study shows that $72 \%$ of the respondents used tube well as a source of drinking water, ${ }^{17} 43.3 \%$ of the respondents were aware about the transmission of diarrheoa through dirty nails and majority $73.3 \%$ of the respondents do not defecate barefoot. ${ }^{16}$

\section{Conclusion and Recommendations:}

Hygienic practice is important when people get adequate education and information. Mass media can play an important role in dissemination of hygienic education to the rural people. There should be extensive health 
Volume 1, Number 2, July 2019

education program for the people about the personal hygiene and sanitation.

\section{References}

1. Environmental sanitation guidelines, Rural Village Water Resources Management Project, 2009.

2. Dwivedi P, Sharma A. N. A Study on Environmental Sanitation, Sanitary Habits and Personal Hygiene among the Baigas of Samnapur Block of Dindori District, MadhyaPradesh, J. Hum. Ecol 2007;1:7-1.0

3. World Health Organization and United Nations Children's Fund Joint Monitoring Programme on Water Supply and Sanitation and Water Supply and Sanitation Collaborative Council, 2012.

4. Thapa M, Sharma AP. Study of Bacteriological Treatment of Water for Rural Communities. Nepal Journal of Science and Technology. Royal Nepal; Academy of Science and Technology, Kathmandu 1999; 1:27-33.

5. Ahmed MF. South Asian Conference on Sanitation, BCHIMES, Between Census Household Information, Monitoring and Evaluation System; 2001.

6. Akter T, Ali A Mehrab. Factors influencing knowledge and practice of hygiene in Water, Sanitation and Hygiene (WASH) programme areas of Bangladesh Rural Advancement Committee. Rural and Remote Health (Internet) 2014; 14: 2628.

7. UNICEF. Rural sanitation, hygiene and water supply. (Online) 2008. Available: http://www.unicef.org/bangladesh/ RURAL Water Sanitation and JHygiene.pdf (Accessed 7 September 2011).

8. Lipson J. The public health benefits of sanitation interventions. EPAR Brief No. 104. University of Washington: Evans School of Public Affairs, 2010.

9. Nath KJ, Chowdhury B, Sengupta A. Study on perception and practice of hygiene and impact on health in India. In Proceedings of South Asia Hygiene Practitioners' Workshop, 1-4 February, Dhaka, Bangladesh. (Online) 2010.

10. Centers for Disease Control. Global WASH-related diseases and contaminants.(Online). 2010.

11. Kabir B, Barua MK, Karim R, Bodiuzzaman M, Rahman M, Mia HA. Contributions of village WASH committee in breaking the cycle of unhygienic behaviours in rural Bangladesh. In: Proceedings of South Asia Hygiene Practitioners' Workshop, 1-44 February, Dhaka, Bangladesh. (Online) 2010.

12. Rajiv Ranjan Karn, Buna Bhandari, and Nilambar Jha a study on personal hygiene and sanitary practices in a rural village of mornag district of Nepal; Journal of Nobel Medical College (2011), 1(2): 39-44.

13. Farah S, Karim M, Akther N, Begum M, \& Begum N. (2015). Knowledge and Practice of Personal Hygiene and Sanitation: A Study in Selected Slums of Dhaka City. Delta Medical College Journal, 3(2), 68-73.

14. Shammi M and Morshed M. Assessment of Practices of Sanitation and Hygiene Comparison of a Declared Sanitation Area to a Non Area of Sirajganj District, Bangladesh; Jahangirnagar Univrsity Environmental Bulletin 2013, 2: 50-60.

15. Bangladesh National Hygiene Baseline Survey 2014. International Centre for Diarrheal Diseases Research, Bangladesh (icddr,b) and WaterAid Bangladesh.
16. Shammi M and Morshed M. Assessment of Practices of Sanitation and Hygiene Comparison of a Declared Sanitation Area to a Non Area of Sirajganj District, Bangladesh; Jahangirnagar Univrsity Environmental Bulletin 2013, 2: 50-60.

17. Begum S, Ahmed M, Sen B. Do Water and Sanitation Interventions Reduce Childhood Diarrhoea? New Evidence from Bangladesh Bangladesh; Development Studies September 2011, XXXIV(3): 6-8 